\title{
Synthesis and Molecular Structure of a Copper Octaiodocorrole
}

\author{
Ivar K. Thomassen, ${ }^{\dagger}$ Laura J. McCormick, ${ }^{\ddagger}{ }^{\mathrm{c}}$ and Abhik Ghosh* ${ }^{*}{ }^{\dagger}$ \\ ${ }^{\dagger}$ Department of Chemistry, UiT-The Arctic University of Norway, Tromsø N-9037, Norway \\ ${ }^{\ddagger}$ Advanced Light Source, Lawrence Berkeley National Laboratory, Berkeley, California 94720-8229, United States
}

\section{Supporting Information}

ABSTRACT: Although rather delicate on account of their propensity to undergo deiodination, $\beta$-octaiodoporphyrinoids are of considerable interest as potential precursors to novel $\beta$-octasubstituted macrocycles. Presented herein are early results of our efforts to synthesize $\beta$-octaiodocorrole derivatives. Oxidative condensation of 3,4-diiodopyrrole and aromatic aldehydes failed to yield free-base octaiodocorroles. Treatment of copper meso-tris ( $p$-cyanophenyl)corrole with $\mathrm{N}$-iodosuccinimide and trifluoroacetic acid over several hours, however, yielded the desired $\beta$-octaiodinated product in $\sim 22 \%$ yield. Singlecrystal X-ray structure determination of the product revealed a strongly saddled corrole macrocycle with metrical parameters very close to those of analogous $\mathrm{Cu}$ octabromocorrole complexes. The compound was also found to exhibit an exceptionally red-shifted Soret maximum (464 $\mathrm{nm}$ in dichloromethane), underscoring the remarkable electronic effect of $\beta$-octaiodo substitution.

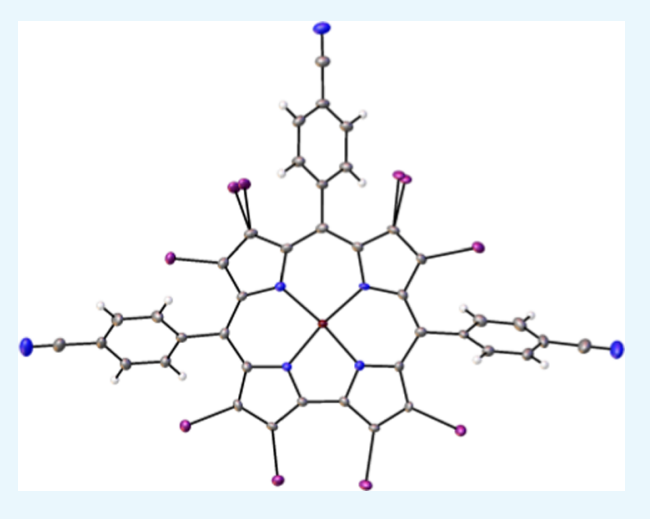

\section{INTRODUCTION}

Compared to $\beta$-octabrominated porphyrins ${ }^{1,2}$ and corroles, ${ }^{3}$ which serve as starting materials for a variety of other $\beta$ octasubstituted macrocycles, ${ }^{4,5}$ polyiodoporphyrinoids remain relatively little explored. Some progress, however, has taken place recently. Thus, we have recently reported a number of $\beta$ octaiodoporphyrin $^{6}$ derivatives and Gross and co-workers have reported several polyiodocorrole derivatives. ${ }^{7-9}$ The latter group has also reported a facile copper-catalyzed transformation of gold $\beta$-iodocorroles to the corresponding $\beta$-trifluoromethyl derivatives. ${ }^{10}$ No $\beta$-octaiodocorrole derivative, however, has been reported to date. ${ }^{11-13}$ Reported herein is the synthesis and single-crystal X-ray structure of copper 2,3,7,8,12,13,17,18octaiodo-5,10,15-(4'-cyanophenyl)corrole ( $\left.\mathrm{Cu}\left[\mathrm{I}_{8} \mathrm{~T} p \mathrm{CNPC}\right]\right)$, the first $\beta$-octaiodocorrole complex.

\section{RESULTS AND DISCUSSION}

Attempts at oxidative condensation of 3,4-diiodopyrrole with aromatic aldehydes via a variety of methods frequently afforded low yields of $\beta$-octaiodoporphyrins ${ }^{6}$ but at best only traces of corroles. Accordingly, we turned our attention to the iodination of copper tris(para-X-phenyl)corrole complexes, $\mathrm{Cu}[\mathrm{T} p \mathrm{XPC}]$, where $\mathrm{X}=\mathrm{OMe}, \mathrm{Me}, \mathrm{CF}_{3}$, and $\mathrm{CN}^{3}$ Periodic acid/iodine $\left(\mathrm{H}_{5} \mathrm{IO}_{6} / \mathrm{I}_{2}\right)$, which we previously used to iodinate $\mathrm{N}$ triisopropylsilylpyrrole, ${ }^{6}$ proved too harsh, resulting in destruction of the $\mathrm{Cu}$ corrole. Attempts at metal-halogen exchange on the $\mathrm{Cu} \beta$-octabromocorroles with $n$-BuLi or Rieke magnesium, ${ }^{14}$ followed by exposure to an iodinating agent, such as $\mathrm{N}$-iodosuccinimide (NIS), proved similarly futile. Interaction with NIS in the presence of trifluoroacetic acid (TFA) led to complete destruction of the corrole, for $\mathrm{X}=\mathrm{OMe}$ and Me. In contrast, for $\mathrm{X}=\mathrm{CF}_{3}$ and $\mathrm{CN}$, mass spectrometric analysis indicated the formation of the desired octaiodocorrole product, $\mathrm{Cu}\left[\mathrm{I}_{8} \mathrm{~T} p \mathrm{XPC}\right]\left(\mathrm{X}=\mathrm{CF}_{3}\right.$ and $\left.\mathrm{CN}\right)$. Unfortunately, for $\mathrm{X}=\mathrm{CF}_{3}$, isolation of the octaiodo product was frustrated by the presence of large quantities of inseparable impurities. For $\mathrm{X}=\mathrm{CN}$, on the other hand, stirring with NIS/TFA at room temperature for several hours led to modest $(\sim 20 \%)$ yields of the desired product, $\mathrm{Cu}\left[\mathrm{I}_{8} \mathrm{~T} p \mathrm{CNPC}\right]$. The same product was also obtained with 1,3-diiodo-5,5-dimethylhydantoin. ${ }^{15}$ Initially, the octaiodo product was contaminated with varying amounts of the $I_{7}$ and other deiodinated compounds. Varying the amount of iodinating agent (10-100 equiv) and the solvents (acetonitrile, dichloromethane, toluene, and mixtures thereof) ultimately led to a protocol affording a $22 \%$ yield of $\mathrm{Cu}\left[\mathrm{I}_{8} \mathrm{~T} p \mathrm{CNPC}\right]$ with no more than $2-3 \%$ of the $\mathrm{I}_{7}$ contaminant (Scheme 1 ).

Full characterization of $\mathrm{Cu}\left[\mathrm{I}_{8} \mathrm{~T} p \mathrm{CNPC}\right]$ was hampered by the poor solubility of the compound in common solvents, presumably reflecting aggregation of the molecule. Thus, ${ }^{1} \mathrm{H}$ NMR spectra proved unobtainable in essentially all solvents $\left(\mathrm{CDCl}_{3}, \mathrm{CD}_{2} \mathrm{Cl}_{2}\right.$, 1,2-dichlorobenzene- $d_{4}$, acetone- $d_{6}, \mathrm{D}_{2} \mathrm{O}$, and pyridine- $d_{5}$ ) except tetrahydrofuran (THF) $-d_{8}$, in which a spectrum was obtained consisting of three doublets of equal intensity, suggesting that the ortho and meta protons of the 10aryl group are accidentally isochronous (Figure 1). Unfortunately, the weak signals frustrated our attempts to carry out a detailed two-dimensional NMR analysis. The poor solubility of the compound also hindered our efforts to obtain X-ray quality crystals. In a stroke of luck, diffusion of heptane vapor into a 1,2-dichlorobenzene solution of a $\sim 70: 30$ mixture of $\mathrm{Cu}$ $\left[\mathrm{I}_{8} \mathrm{~T} p \mathrm{CNPC}\right] / \mathrm{Cu}\left[\mathrm{I}_{7} \mathrm{~T} p \mathrm{CNPC}\right]$ (the product of an earlier, less

Received: March 31, 2018

Accepted: April 23, 2018

Published: May 9, 2018 


\section{Scheme 1}
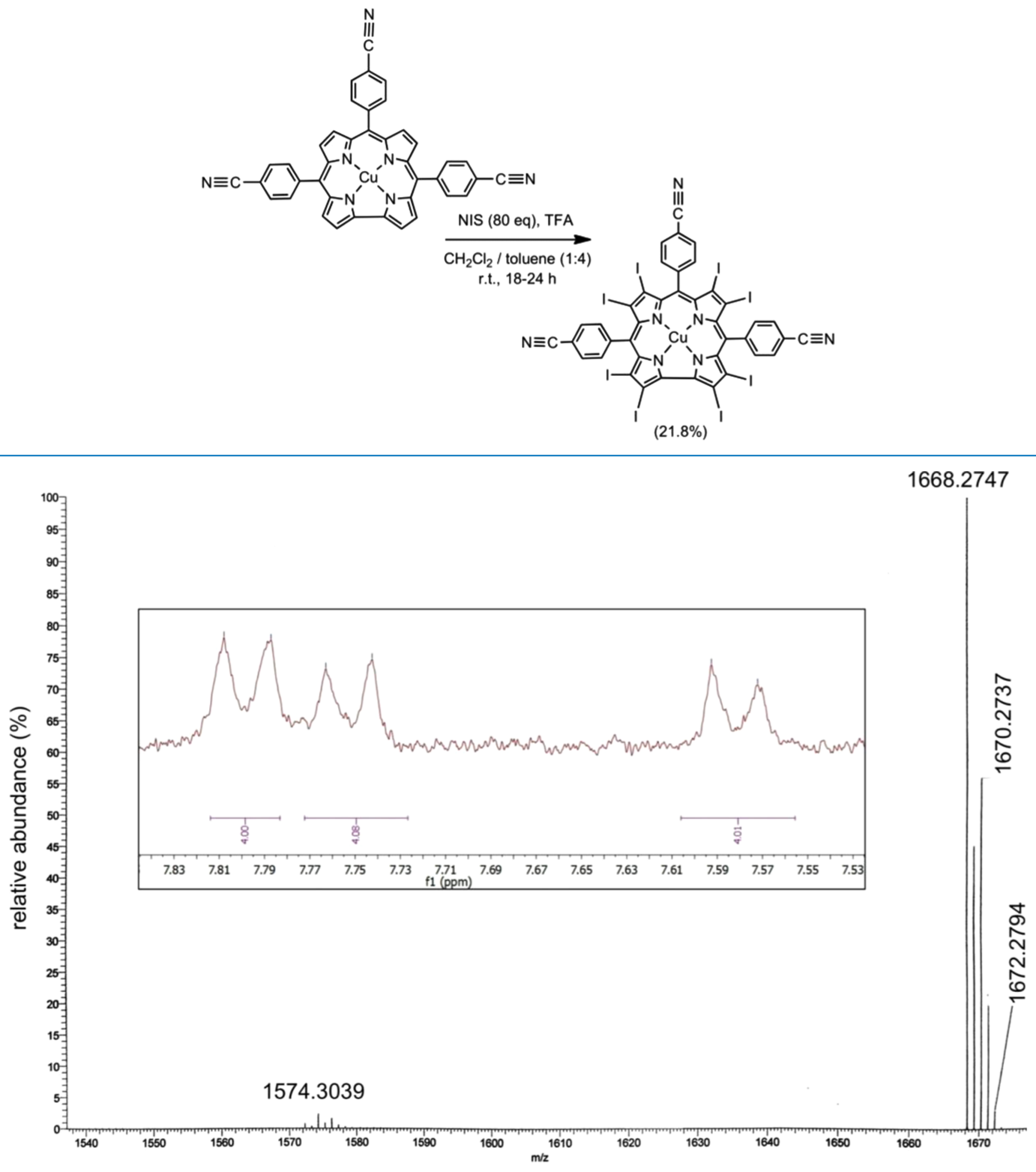

Figure 1. High-resolution electrospray ionization (ESI) mass spectrum of $\mathrm{Cu}\left[\mathrm{I}_{8} \mathrm{~T} p \mathrm{CNPC}\right]$ in negative mode. Inset: ${ }^{1} \mathrm{H}$ NMR spectrum in THF- $d_{8}$.

optimized synthetic protocol) afforded crystals, which proved amenable to single-crystal X-ray structure determination (Figure 2 and Table 1).

As expected for a sterically hindered $\mathrm{Cu}$ corrole, the $\mathrm{X}$-ray structure revealed a strongly but not exceptionally saddled macrocycle geometry. ${ }^{13,16}$ Table 2 provides a comparison of key metrical parameters of $\mathrm{Cu}\left[\mathrm{I}_{8} \mathrm{~T} p \mathrm{CNPC}\right]$ and of other, pertinent $\mathrm{Cu}$ corroles. ${ }^{17-24}$ Thus, despite the significantly higher van der Waals radius of $\mathrm{I}(2.15 \AA)$ relative to $\mathrm{Br}(1.95$ $\AA),{ }^{25,26}$ the $\mathrm{Cu}-\mathrm{N}$ distances and saddling dihedrals for $\mathrm{Cu}\left[\mathrm{I}_{8} \mathrm{~T} p \mathrm{CNPC}\right]$ (see Figure 2) were found to be nearly identical to those of $\mathrm{Cu} \beta$-octabromo-meso-triarylcorroles, ${ }^{19-21}$ suggesting that peripheral I...I interactions may not be as repulsive as implied by iodine's van der Waals radius. We may further note that the present structure is somewhat more saddled than a $\mathrm{Cu}$ undecaarylcorrole $\mathrm{e}^{22,23}$ but distinctly less so 


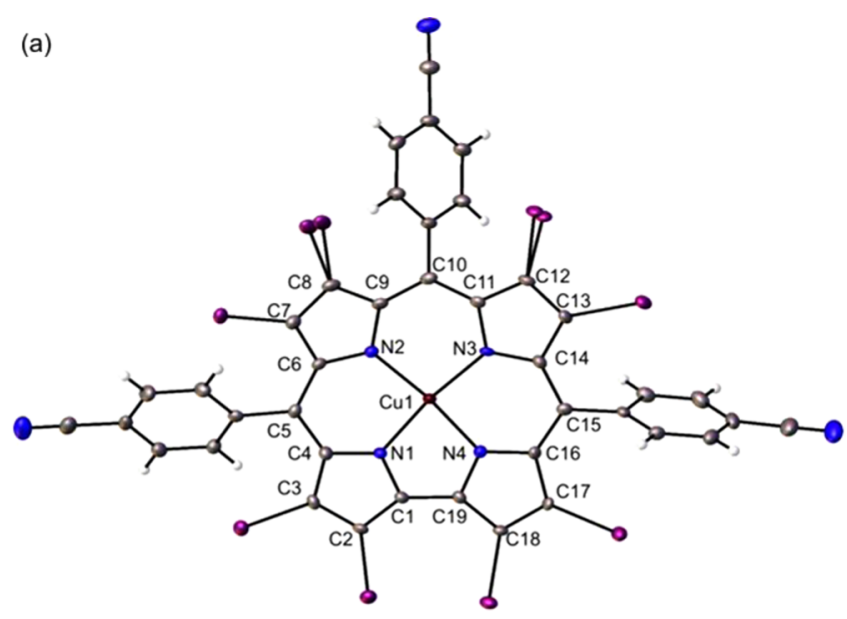

(b)

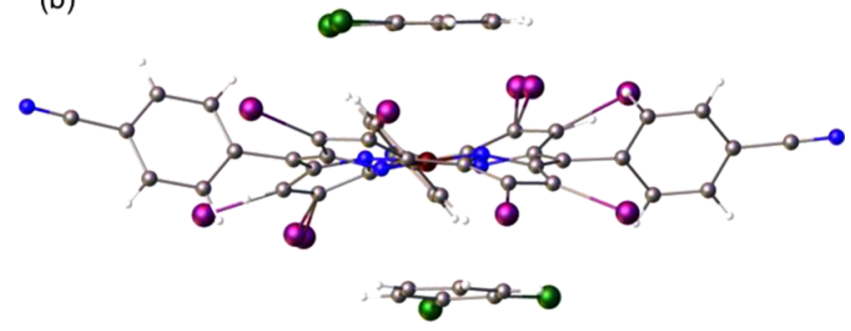

Figure 2. Thermal ellipsoid plots (50\%) for $\mathrm{Cu}\left[\mathrm{I}_{8} \mathrm{~T} p \mathrm{CNPC}\right]$ : (a) top and (b) side views, the latter showing $\pi$-stacking interactions with two molecules of 1,2-dichlorobenzene. Selected distances $(\AA)$ : Cu1-N1 1.925(3), Cu1-N2 1.919(3), Cu1-N3 1.925(3), and Cu1-N4 1.916(3). Saddling dihedrals $\left(^{\circ}\right)$ : C2-C1-C19-C18 45.3(8), C3-C4-C6-C7 -65.5(12), C8-C9-C11-C12 57.3(11), and C13-C14-C16-C17 $-68.4(12)$.

Table 1. Crystallographic Data for $\mathrm{Cu}\left[\mathrm{I}_{7.64} \mathrm{~T} p \mathrm{CNPC}\right] \cdot 4(1,2-$ $\mathrm{C}_{6} \mathrm{H}_{4} \mathrm{Cl}_{2}$ )

$\begin{array}{ll}\text { chemical formula } & \mathrm{C}_{64} \mathrm{H}_{28.36} \mathrm{I}_{7.64} \mathrm{Cl}_{8} \mathrm{~N}_{7} \mathrm{Cu} \\ \text { formula mass } & 2211.86 \\ \text { crystal system } & \text { triclinic } \\ \text { space group } & P \overline{1} \\ \lambda(\AA) & 0.7288(1) \\ a(\AA) & 13.9951(7) \\ b(\AA) & 14.2730(8) \\ c(\AA) & 17.8450(10) \\ \alpha(\text { deg}) & 111.769(2) \\ \beta(\text { deg }) & 91.652(2) \\ \gamma(\text { deg }) & 90.047(2) \\ Z & 2 \\ V(\AA) & 3308.7(3) \\ \text { temperature }(\mathrm{K}) & 100(2) \\ \text { density (g cm } & -3) \\ \text { meas. reflections } & 2.220 \\ \text { unique reflections } & 126292 \\ \text { parameters } & 21097 \\ \text { restraints } & 803 \\ R_{\text {int }} & 0 \\ \theta \text { range (deg) } & 0.0399 \\ R_{1}, \text { w } R_{2} \text { all data } & 1.493-31.899 \\ S(\text { GooF) all data } & 0.0596,0.0740 \\ \text { max/min res. dens. }\left(\mathrm{e} \AA^{-3}\right) & 1.157 \\ & 0.911 /-1.270\end{array}$

than a $\mathrm{Cu} \beta$-octakis(trifluoromethyl)-meso-triarylcorrole. ${ }^{24} \mathrm{An}$ interesting aspect of the crystal structure is that the metal- locorrole occurs sandwiched between two 1,2-dichlorobenzene molecules, suggesting that $\pi$-stacking interactions account for the significant solubility of the complex in 1,2-dichlorobenzene.

The UV-vis spectrum of $\mathrm{Cu}\left[\mathrm{I}_{8} \mathrm{~T} p \mathrm{CNPC}\right]$ in $\mathrm{CH}_{2} \mathrm{Cl}_{2}$ exhibits a dramatically red-shifted Soret maximum $(464 \mathrm{~nm})$, relative to $\mathrm{Cu}[\mathrm{TPC}](413 \mathrm{~nm}),{ }^{3} \mathrm{Cu}\left[\mathrm{Br}_{8} \mathrm{TPC}\right](439 \mathrm{~nm}),{ }^{3}$ and even $\mathrm{Cu}\left[\left(\mathrm{CF}_{3}\right)_{8} \mathrm{TPC}\right](459 \mathrm{~nm})$ (Figure 3$) .{ }^{27}$ Given that $\mathrm{Cu}\left[\mathrm{I}_{8} \mathrm{~T} p \mathrm{CNPC}\right]$ is in all likelihood no more saddled than $\mathrm{Cu}\left[\mathrm{Br}_{8} \mathrm{TPC}\right]$, the strongly red-shifted Soret maximum of the former provides a nice illustration of the unique electronic effect of the $\beta$-octaiodo substitution. Interestingly, the Soret maximum of $\mathrm{Cu}\left[\mathrm{I}_{8} \mathrm{~T} p \mathrm{CNPC}\right]$ exhibits a mild redshift in pyridine $\left(\lambda_{\max }=468 \mathrm{~nm}\right)$, potentially indicating halogen bonding interactions with that solvent.

\section{CONCLUSIONS}

$\beta$-Octaiodoporphyrinoids are fragile molecules that readily undergo deiodination. Careful choice of starting materials and mild reaction conditions has allowed the synthesis and subsequently single-crystal X-ray structure determination of the first $\beta$-octaiodocorrole derivative, viz., copper $2,3,7,8,12,13,17,18$-octaiodo-5,10,15-(4'-cyanophenyl)corrole $\left(\mathrm{Cu}\left[\mathrm{I}_{8} \mathrm{~T} p \mathrm{CNPC}\right]\right)$. The complex exhibits a strongly saddled corrole macrocycle with metrical parameters very similar to those of analogous $\mathrm{Cu} \beta$-octabromocorroles and an unexpectedly red-shifted Soret maximum. Ongoing research in our laboratory focuses on developing additional, more general routes to octaiodocorrole derivatives as well as on exploiting these unique and delicate molecules as starting materials for new functionalized corroles.

\section{EXPERIMENTAL SECTION}

Materials and Instrumentation. 4-Cyanobenzaldehyde, $\mathrm{N}$-iodosuccinimide, and trifluoroacetic acid (HPLC-grade, $\geq 99.0 \%$ ) were purchased from Sigma-Aldrich and used without further purification. Pyrrole (Sigma-Aldrich) was purified by passing through a pad of basic aluminum oxide 60 (activity I, 0.063-0.200 mm particle size, Merck Millipore). Copper 5,10,15-tris (4'-cyanophenyl)corrole was prepared via a one-pot protocol derived by modification of a previously reported procedure (for which the purification steps did not work well in our hands). ${ }^{28}$ Silica gel $150(35-70 \mu \mathrm{m}$ particle size, Davisil) and neutral aluminum oxide (activity I, 0.050-0.150 mm particle size, Sigma) were used as purchased.

Ultraviolet-visible spectra were recorded on an HP 8453 spectrophotometer at room temperature in $\mathrm{CH}_{2} \mathrm{Cl}_{2} \cdot{ }^{1} \mathrm{H} \mathrm{NMR}$ spectra were recorded at room temperature on a Mercury Plus Varian spectrometer $(400 \mathrm{MHz})$, and high-resolution electrospray ionization (ESI) mass spectra were recorded on an LTQ Orbitrap XL spectrometer.

Synthetic Methods. Copper 5,10,15-Tris(4-cyanophenyl)corrole. 4-Cyanobenzaldehyde (520 mg, $4 \mathrm{mmol})$ was dissolved in pyrrole $(400 \mathrm{mg}, 6 \mathrm{mmol}$ ) and to the stirred mixture was added a solution $(40 \mu \mathrm{L})$ of $10 \%$ trifluoroacetic acid in dichloromethane at room temperature. After $10 \mathrm{~min}$, the solution was diluted with dichloromethane $(10 \mathrm{~mL})$ and a solution of 2,3-dichloro-5,6-dicyano-1,4-benzoquinone ( $1 \mathrm{~g}, 4.8$ $\mathrm{mmol})$ in 1:1 toluene/THF $(4 \mathrm{~mL})$ was added. After $5 \mathrm{~min}$ of stirring, the mixture was further diluted with dichloromethane $(40 \mathrm{~mL})$ and extracted twice with a saturated solution of sodium bicarbonate $(50 \mathrm{~mL}$ each time) and twice with distilled water (50 mL each time). The organic phase was dried with 
Table 2. Copper-Nitrogen Distances $(\AA)$ and Saddling Dihedrals $\left(^{\circ}\right)$ for Selected Cu Corroles

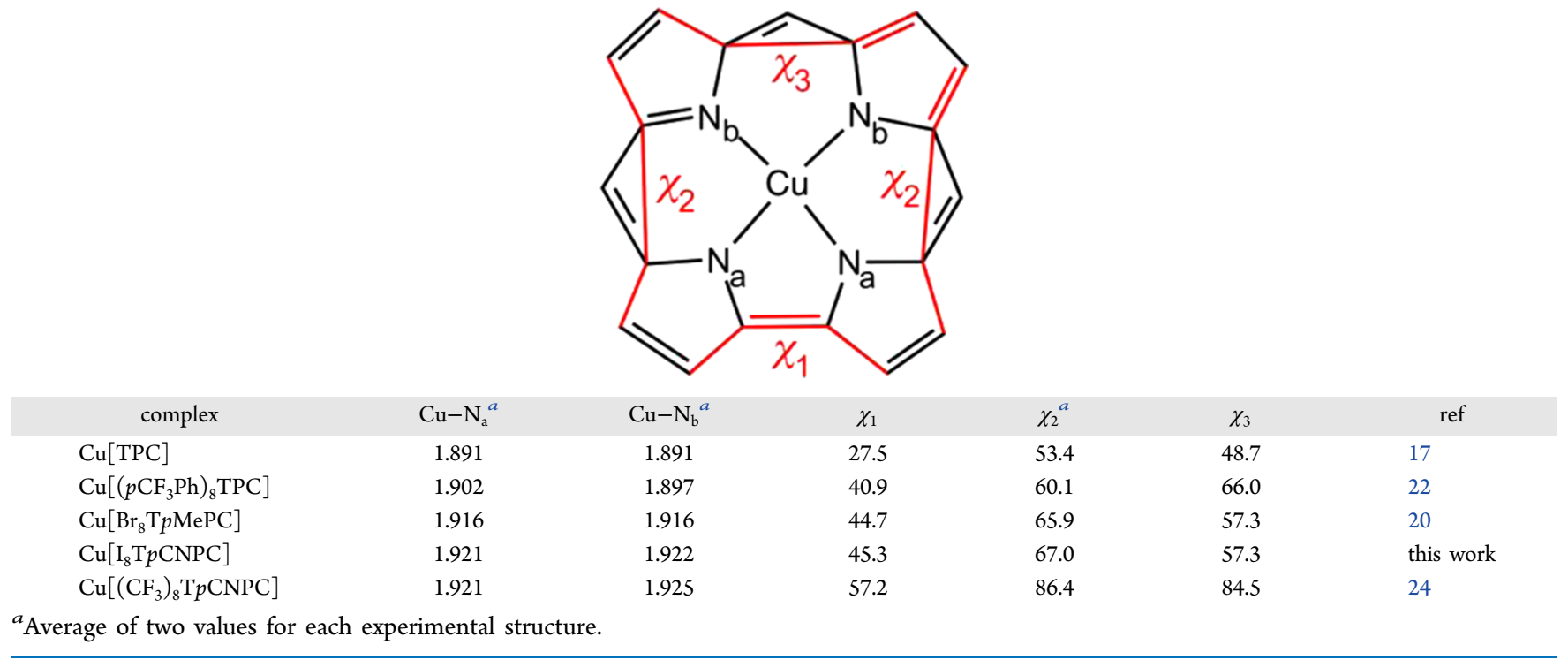

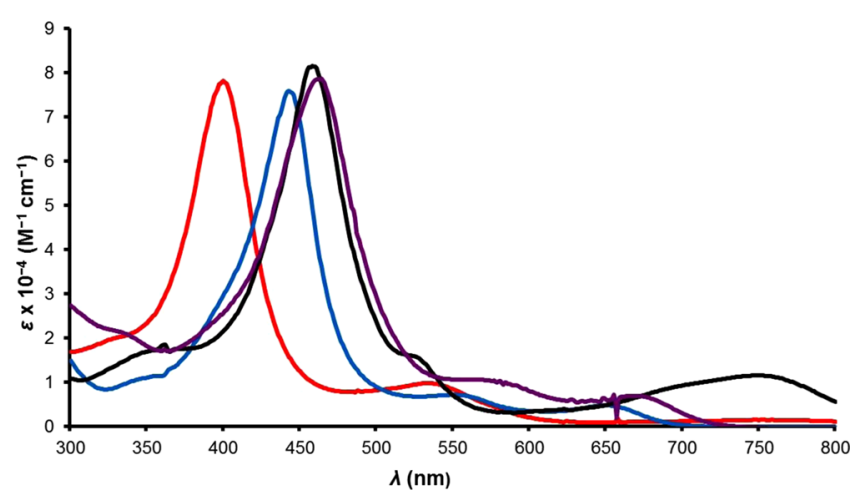

Figure 3. Comparison of the UV-vis spectra (dichloromethane) of $\mathrm{Cu}[\mathrm{TPC}]$ (red), $\mathrm{Cu}\left[\mathrm{Br}_{8} \mathrm{TPC}\right]$ (blue), $\mathrm{Cu}\left[\left(\mathrm{CF}_{3}\right)_{8} \mathrm{TPC}\right]$ (black), and $\mathrm{Cu}\left[\mathrm{I}_{8} \mathrm{Tp} \mathrm{CNPC}\right]$ (purple).

anhydrous sodium sulfate and filtered. The filtrate was evaporated to dryness and the residue, whose crude weight was noted, was redissolved in pyridine $(50 \mathrm{~mL})$. Copper (II) acetate hydrate ( 1.1 equiv relative to the crude product) was added, and the solution was left to stir for $30 \mathrm{~min}$. Upon removal of the solvent in vacuo, the solid residue was dissolved in a minimum volume of dichloromethane and chromatographed on silica gel column (with initially $\mathrm{CH}_{2} \mathrm{Cl}_{2}$ and then with $10 \%$ EtOAc in $\mathrm{CH}_{2} \mathrm{Cl}_{2}$ as eluent) to afford $\mathrm{Cu}$ [TpCNPC] as a brown solid (81.6 $\mathrm{mg}, 9.2 \%)$. All analytical data were consistent with previously reported values. ${ }^{28}$

Copper 2,3,7,8,12,13,17,18-Octaiodo-5, 10,15-(4' cyanophenyl)corrole, $\mathrm{Cu}\left[\mathrm{I}_{8} \mathrm{TpCNPC}\right]$. To a stirred solution of $\mathrm{Cu}[\mathrm{T} p \mathrm{CNPC}](5.8 \mathrm{mg}, 0.009 \mathrm{mmol})$ in dichloromethane (2 $\mathrm{mL})$ at room temperature, was added $N$-iodosuccinimide (160 $\mathrm{mg}, 0.7 \mathrm{mmol}$ ) dissolved (by sonication, if necessary) in toluene $(8 \mathrm{~mL})$ containing a few drops of trifluoroacetic acid. The resulting solution was stirred overnight $(19 \mathrm{~h})$. Upon dilution with toluene $(15 \mathrm{~mL})$, the solution was washed twice with water $(2 \times 25 \mathrm{~mL})$. The combined aqueous phases were extracted with toluene $(25 \mathrm{~mL})$, and the combined organic phases were then dried with anhydrous magnesium sulfate and filtered. The filtrate was evaporated to dryness, and the resulting residue was dissolved in dichloromethane and chromatographed on a neutral alumina column with 4:1 dichloromethane/ethyl acetate as an olive-green solid $(3.3 \mathrm{mg}$, $21.8 \%)$. UV-vis $\left(\mathrm{CH}_{2} \mathrm{Cl}_{2}\right) \lambda_{\max }\left[\mathrm{nm}, \epsilon \times 10^{-4}\left(\mathrm{M}^{-1} \mathrm{~cm}^{-1}\right)\right]$ : 464 (7.85), 567 (1.06), 668 (0.69). ${ }^{1} \mathrm{H}$ NMR (400 MHz, THF$\left.d_{8}, \delta\right): 7.58\left(\mathrm{~d}, 4 \mathrm{H},{ }^{3} J_{\mathrm{HH}}=8.2 \mathrm{~Hz}\right), 7.75\left(\mathrm{~d}, 4 \mathrm{H},{ }^{3} J_{\mathrm{HH}}=8.2 \mathrm{~Hz}\right)$, $7.80\left(\mathrm{~d}, 4 \mathrm{H},{ }^{3} J_{\mathrm{HH}}=8.3 \mathrm{~Hz}\right)$. High-resolution mass spectrometry (ESI in methanol): $[\mathrm{M}]^{-}=1668.2812$ (expt), 1668.2813 (calcd for $\left.\mathrm{CuC}_{40} \mathrm{H}_{12} \mathrm{~N}_{7} \mathrm{I}_{8}\right)$. Crystals suitable for $\mathrm{X}$-ray analysis were obtained by vapor diffusion of heptane into a concentrated 1,2dichlorobenzene solution.

X-ray Structure Determination. X-ray data for $\mathrm{Cu}$ $\left[\mathrm{I}_{8} \mathrm{~T} p \mathrm{CNPC}\right]$ were collected on beamline 12.2.1 at the Advanced Light Source, Lawrence Berkeley National Laboratory. The crystal, an orange lath $(0.080 \mathrm{~mm} \times 0.010 \mathrm{~mm} \times$ $0.010 \mathrm{~mm})$, was mounted on a MiTeGen kapton loop and placed in a $100(2) \mathrm{K}$ nitrogen cold stream provided by an Oxford Cryostream 800 Plus low-temperature apparatus on the goniometer head of a Bruker D8 diffractometer equipped with a PHOTON II CPAD detector operating in shutterless mode. Diffraction data were collected using synchrotron radiation monochromated using silicon (111) to a wavelength of 0.7288(1) A. An approximate full-sphere of data was collected using a combination of $\phi$ and $\omega$ scans with a scan speed of $0.5 \mathrm{~s}$ per $4^{\circ}$ for the $\phi$ scans and 0.5 and $1 \mathrm{~s}$ per degree for the $\omega$ scans at $2 \theta=0$ and -20 , respectively. Absorption corrections were applied using SADABS. ${ }^{29}$ The structure was solved by intrinsic phasing (SHELXT) ${ }^{30}$ and refined by full-matrix least squares on $F^{2}$ (SHELXL-2014) ${ }^{31}$ using the ShelXle GUI. ${ }^{32}$ Appropriate scattering factors were applied using the $\mathrm{XDISP}^{33}$ program within the WinGX suite. ${ }^{34}$ All nonhydrogen atoms were refined anisotropically. Hydrogen atoms were geometrically calculated and refined as riding atoms. Electron density holes near the iodine atoms at the $\mathrm{C} 7$ and $\mathrm{C} 13$ positions indicated that these atoms do not have $100 \%$ occupancy, and the occupancies of iodine atoms at $\mathrm{C} 7$ and $\mathrm{C} 13$ ( $\mathrm{I}_{3}$ and $\mathrm{I}_{6}$ in the cif) were allowed to freely refine. The relative occupancies of these atoms refined to approximately 85 and $80 \%$, consistent with a $\sim 35 \%$ contamination of the crystal by the $I_{7}$ species. A small amount of positional disorder was found for the iodine atoms bound to $\mathrm{C} 8$ and $\mathrm{C} 12$. Accordingly, the two atoms were each modeled over two sites with complementary occupancies. 


\section{ASSOCIATED CONTENT}

\section{S Supporting Information}

The Supporting Information is available free of charge on the ACS Publications website at DOI: 10.1021/acsomega.8b00616.

Crystallographic data (CIF)

\section{AUTHOR INFORMATION}

\section{Corresponding Author}

*E-mail: abhik.ghosh@uit.no. Tel: +47 45476145.

\section{ORCID}

Laura J. M Cormick: 0000-0002-6634-4717

Abhik Ghosh: 0000-0003-1161-6364

Notes

The authors declare no competing financial interest.

\section{ACKNOWLEDGMENTS}

This work was supported by grants 231086 and 262229 of the Research Council of Norway and by the Advanced Light Source, Berkeley, California. The Advanced Light Source is supported by the Director, Office of Science, Office of Basic Energy Sciences, of the U.S. Department of Energy under Contract No. DE-AC02-05CH11231.

\section{REFERENCES}

(1) Dolphin, D.; Traylor, T. G.; Xie, L. Y. Polyhaloporphyrins: Unusual Ligands for Metals and Metal-Catalyzed Oxidations. Acc. Chem. Res. 1998, 27, 31-41.

(2) Ghosh, A.; Halvorsen, I.; Nilsen, H. J.; Steene, E.; Wondimagegn, T.; Lie, R.; van Caemelbecke, E.; Guo, N.; Ou, Z.; Kadish, K. M. Electrochemistry of Nickel and Copper $\beta$-Octahalogeno-mesotetraarylporphyrins. Evidence for Important Role Played by Saddling-Induced $\operatorname{Metal}\left(\mathrm{d}_{\mathrm{xz}-\mathrm{y} 2}\right)$-Porphyrin(" $\mathrm{a}_{2 \mathrm{u}}$ ") Orbital Interactions. J. Phys. Chem. B 2001, 105, 8120-8124.

(3) Wasbotten, I. H.; Wondimagegn, T.; Ghosh, A. Electronic Absorption, Resonance Raman, and Electrochemical Studies of Planar and Saddled Copper(III) Meso-Triarylcorroles. Highly SubstituentSensitive Soret Bands as a Distinctive Feature of High-Valent Transition Metal Corroles. J. Am. Chem. Soc. 2002, 124, 8104-8116.

(4) Medforth, C. J.; Smith, K. M. The synthesis and solution conformation of dodecaphenylporphyrin. Tetrahedron Lett. 1990, 31, $5583-5586$.

(5) Liu, C.; Chen, Q. Y. Fluoroalkylation of Porphyrins: A Facile Synthesis of Trifluoromethylated Porphyrins by a Palladium-Catalyzed Cross-Coupling Reaction. Eur. J. Org. Chem. 2005, 2005, 3680-3686.

(6) Thomassen, I. K.; Vazquez-Lima, H.; Gagnon, K. J.; Ghosh, A. Octaiodoporphyrin. Inorg. Chem. 2015, 54, 11493-11497.

(7) Vestfrid, J.; Botoshansky, M.; Palmer, J. H.; Durrell, A. C.; Gray, H. B.; Gross, Z. Iodinated Aluminum(III) Corroles with Long-Lived Triplet Excited States. J. Am. Chem. Soc. 2011, 133, 12899-12901.

(8) Vestfrid, J.; Goldberg, I.; Gross, Z. Tuning the Photophysical and Redox Properties of Metallocorroles by Iodination. Inorg. Chem. 2014, 53, 10536-10542.

(9) Sudhakar, K.; Mahammed, A.; Fridman, N.; Gross, Z. Iodinated cobalt corroles. J. Porphyrins Phthalocyanines 2017, 21, 900-907.

(10) Soll, M.; Sudhakar, K.; Fridman, N.; Müller, A.; Röder, B.; Gross, Z. One-Pot Conversion of Fluorophores to Phosphorophores. Org. Lett. 2016, 18, 5840-5843.

(11) Orłowski, R.; Gryko, D.; Gryko, D. T. Synthesis of Corroles and Their Heteroanalogs. Chem. Rev. 2017, 117, 3102-3137.

(12) Barata, J. F. B.; Neves, M. G. P. M. S.; Faustino, A. F.; Tomé, A. C.; Cavaleiro, J. A. S. Strategies for Corrole Functionalization. Chem. Rev. 2017, 117, 3192-3253.

(13) Ghosh, A. Electronic Structure of Corrole Derivatives: Insights from Molecular Structures, Spectroscopy, Electrochemistry, and Quantum Chemical Calculations. Chem. Rev. 2017, 117, 3798-3881.
(14) Rieke, R. D. Preparation of Organometallic Compounds from Highly Reactive Metal Powders. Science 1989, 246, 1260-1264.

(15) Orazi, O. O.; Corral, A.; Bertorello, H. E. N-Iodohydantoins. II. Iodinations with 1,3-Diiodo-5,5-dimethylhydantoin. J. Org. Chem. 1965, 30, 1101-1104.

(16) Thomas, K. E.; Alemayehu, A. B.; Conradie, J.; Beavers, C. M.; Ghosh, A. The Structural Chemistry of Metallocorroles: Combined XRay Crystallography and Quantum Chemistry Studies Afford Unique Insights. Acc. Chem. Res. 2012, 45, 1203-1214.

(17) Brückner, C.; Briñas, R. P.; Bauer, J. A. K. X-ray Structure and Variable Temperature NMR Spectra of [meso-Triarylcorrolato]copper(III). Inorg. Chem. 2003, 42, 4495-4497.

(18) Alemayehu, A. B.; Gonzalez, E.; Hansen, L. K.; Ghosh, A. Copper Corroles Are Inherently Saddled. Inorg. Chem. 2009, 48, 7794-7799.

(19) Alemayehu, A. B.; Hansen, L. K.; Ghosh, A. Nonplanar, Noninnocent, and Chiral: A Strongly Saddled Metallocorrole. Inorg. Chem. 2010, 49, 7608-7610.

(20) Thomas, K. E.; Vazquez-Lima, H.; Fang, Y.; Song, Y.; Gagnon, K. J.; Beavers, C. M.; Kadish, K. M.; Ghosh, A. Ligand Noninnocence in Coinage Metal Corroles: A Silver Knife-Edge. Chem. - Eur. J. 2015, $21,16839-16847$.

(21) Thomas, K. E.; McCormick, L. J.; Carrié, D.; Vazquez-Lima, H.; Simonneaux, G.; Ghosh, A. Halterman Corroles and Their Use as a Probe of the Conformational Dynamics of the Inherently Chiral Copper Corrole Chromophore. Inorg. Chem. 2018, 57, 4270.

(22) Berg, S.; Thomas, K. E.; Beavers, C. M.; Ghosh, A. Undecaphenylcorroles. Inorg. Chem. 2012, 51, 9911-9916.

(23) Gao, D.; Canard, G.; Giorgi, M.; Balaban, S. Synthesis and Characterization of Copper Undecaarylcorroles and the First Undecaarylcorrole Free Base. Eur. J. Inorg. Chem. 2012, 2012, $5915-5920$

(24) Thomas, K. E.; Conradie, J.; Hansen, L. K.; Ghosh, A. A Metallocorrole with Orthogonal Pyrrole Rings. Eur. J. Inorg. Chem. 2011, 2011, 1865-1870.

(25) Bondi, A. van der Waals Volumes and Radii. J. Phys. Chem. 1964, 68, 441-451.

(26) Rowland, R. S.; Taylor, R. Intermolecular Nonbonded Contact Distances in Organic Crystal Structures: Comparison with Distances Expected from van der Waals Radii. J. Phys. Chem. 1996, 100, 73847391.

(27) Thomas, K. E.; Wasbotten, I. H.; Ghosh, A. Copper $\beta$ Octakis(Trifluoromethyl)Corroles: New Paradigms for Ligand Substituent Effects in Transition Metal Complexes. Inorg. Chem. 2008, 47, 10469-10478.

(28) Gryko, D. T.; Koszarna, B. Refined methods for the synthesis of meso-substituted $\mathrm{A}_{3}$ - and trans- $\mathrm{A}_{2} \mathrm{~B}$-corroles. Org. Biomol. Chem. 2003, $1,350-357$.

(29) Krause, L.; Herbst-Irmer, R.; Sheldrick, G. M.; Stalke, D. Comparison of silver and molybdenum microfocus $\mathrm{X}$-ray sources for single-crystal structure determination. J. Appl. Crystallogr. 2015, 48, 310.

(30) Sheldrick, G. M. SHELXT - Integrated Space-Group and Crystal-Structure Determination. Acta Crystallogr., Sect. A: Found. Adv. 2015, 71, 3-8.

(31) Sheldrick, G. M. Crystal Structure Refinement with SHELXL. Acta Crystallogr., Sect. C: Struct. Chem. 2015, 71, 3-8.

(32) Hübschle, C. B.; Sheldrick, G. M.; Dittrich, B. ShelXle: a Qt graphical user interface for SHELXL. J. Appl. Crystallogr. 2011, 44, $1281-1284$.

(33) Kissel, L.; Pratt, R. H. Corrections to tabulated anomalousscattering factors. Acta Crystallogr., Sect. A: Found. Adv. 1990, 46, 170175 .

(34) Farrugia, L. J. WinGX and ORTEP for Windows: an update. J. Appl. Crystallogr. 2012, 45, 849-854. 